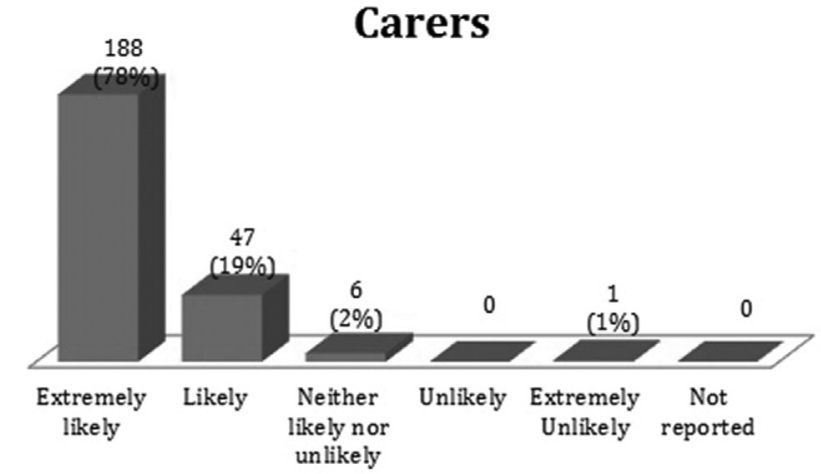

Abstract G443(P) Figure 1 Carers

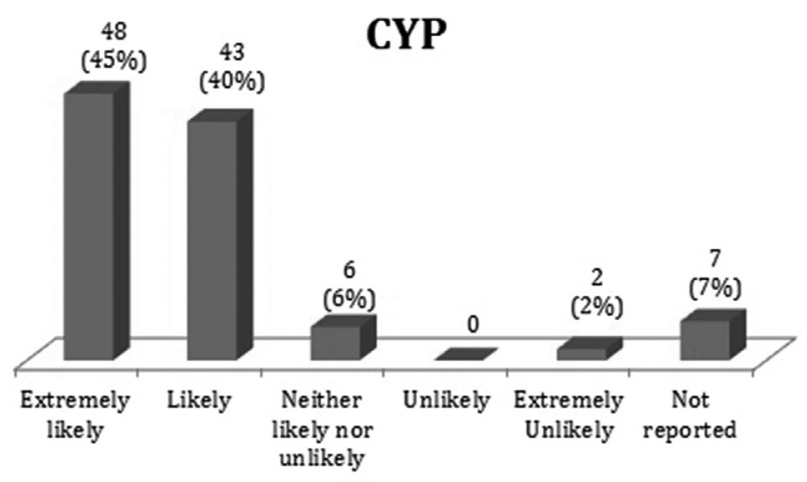

Abstract G443(P) Figure 2 CYP

Results In total 348 forms (106 by CYP and 242 by carers) were completed over the 6 weeks period. The responses across individual questions were highly correlated. See Figures 1 and 2. Conclusion The total number of responses collected is a good representative sample of our caseload. Both CYP and carers report high satisfaction score about their experience with the doctor at clinic appointments. 97\% of carers and 85\% of CYP were either extremely likely or very likely to recommend our service to friends and families. Using a validated tool asking a single question in a busy outpatient setting, we have been able to collect robust evidence about the quality of our service. We plan to use this survey to positively influence commissioners for service development.

\section{G444(P) AN AUDIT OF THE MANAGEMENT OF ANAPHYLAXIS IN CHILDREN IN A DISTRICT GENERAL HOSPITAL}

C Mclaughlin, J Costa, A Aralihond. Paediatrics, St Peter Hospital, Chertsey, UK

\subsection{6/archdischild-2015-308599.398}

Aims To assess how management of anaphylaxis in children complies with local and national guidance.

Methods Retrospective review of 20 cases of paediatric anaphylaxis, diagnosis agreed by consensus between two physicians.

Results Features of the acute reaction were well documented (Figure 1). However only $75 \%$ of children had their blood pressure recorded. The circumstances around the reaction were also well documented and likely triggers identified in all cases. 95\% implicated a food allergen; $63 \%$ of these were nuts or nutcontaining products.

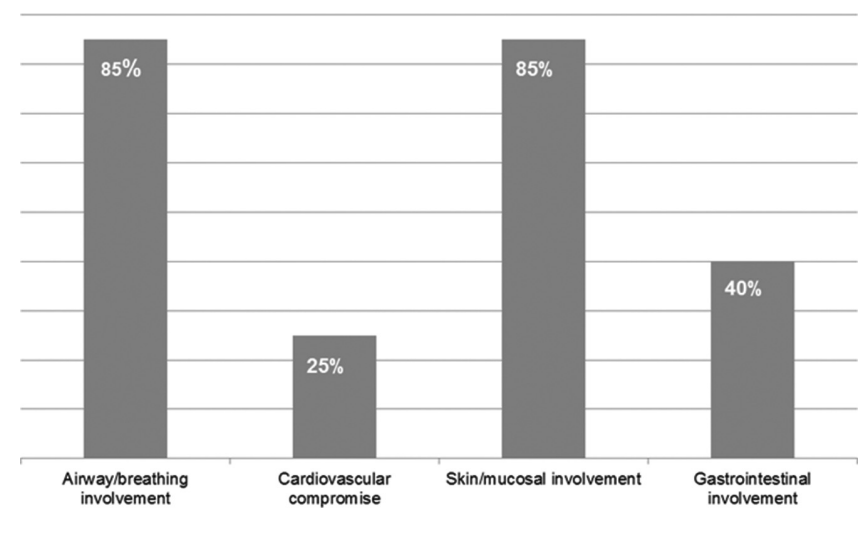

Abstract G444(P) Figure 1

$85 \%$ of children received IM adrenaline, mostly pre-hospital and often by parents (Figure 2). Steroids formed part of the acute management in $95 \%$ of cases, and antihistamines in $100 \%$. $75 \%$ of children were discharged with a course of steroids and antihistamines.

The clinical timescale was less well recorded; 30\% did not have the time of the onset of the reaction documented, and $27 \%$ of children who received pre-hospital adrenaline did not have the time documented.

All children were observed for $6 \mathrm{~h}$ minimum. Documentation of counselling was poor with only $35 \%$ receiving allergen avoidance advice and 20\% warned about the possibility of biphasic reaction. An adrenaline auto-injector (AAI) was offered to $70 \%$. $57 \%$ of those received a documented explanation and demonstration of its use. 95\% were discharged with a GP letter and $80 \%$ had a specialist allergy referral.

Discussion and conclusion The results revealed opportunities for improvement. There is a high standard of history-taking and examination, though an estimated timescale is often not obtained and blood pressure is not consistently measured. Documentation of counselling needs improvement. The pharmacological management of anaphylaxis is excellent in the acute setting but substandard at discharge with children leaving hospital without antihistamines, oral steroids and most importantly AAIs. The proportion receiving prompt pre-hospital treatment with their own AAIs highlights their usefulness and the need to ensure they are prescribed to children at risk.

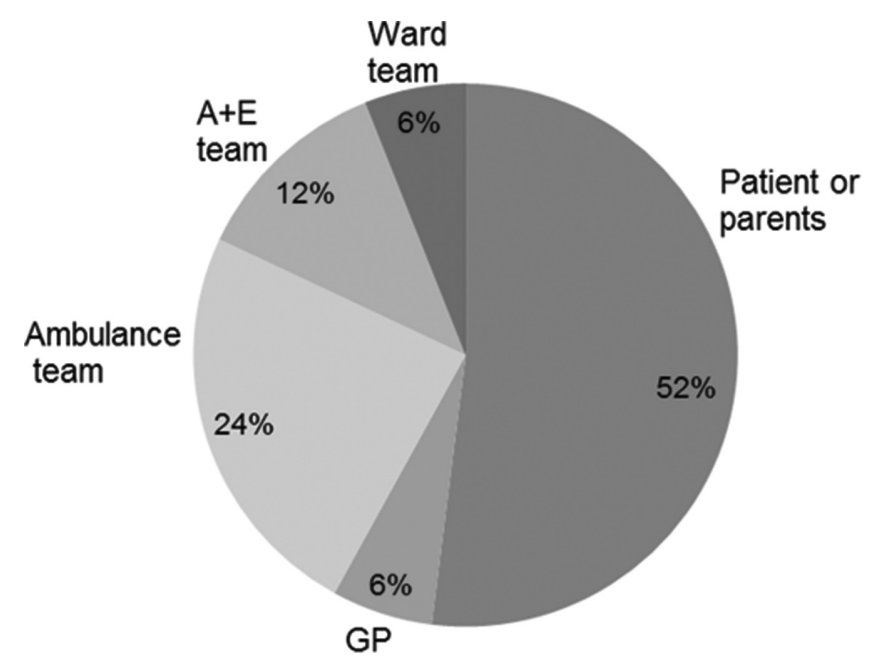

Abstract G444(P) Figure 2 Groups administering adrenaline 
Overall there is good adherence to guidance but simple measures such as a proforma, patient leaflet and personalised allergy action plan available for printing with the local guideline could further optimise patient care. A re-audit to assess the impact of these interventions is planned for 2015 .

\section{G445(P) DIAGNOSIS OF AN INFECTIOUS PROCESS IN NEWBORNS BORN BY MOTHERS WITH CHRONIC INFLAMMATORY GYNAECOLOGICAL DISEASES}

'LL Kravchenko, 'MA Levkovich, ${ }^{2}$ II Krukier, ${ }^{1} M V$ Pyatikova, 'LM Zaurova, ${ }^{1}$ AA Afonin. ${ }^{1}$ Pediatric Department, Rostov Scientific-Research Institute of Obstetrics and Pediatrics, Rostov-on-Don, Russia; '2Department of Biomedical Problems, Rostov Scientific-Research Institute of Obstetrics and Pediatrics, Rostov-on-Don, Russia

10.1136/archdischild-2015-308599.399

Aims To study indices of the cytokine state in umbilical blood of newborns born by women with chronic inflammatory gynaecological diseases in case of a late manifestation of the infectious process.

Methods 37 newborns born by women with chronic inflammatory gynaecological diseases were examined. The levels of interleukin-2 (IL-2), tumour necrosis factor (TNF- $\alpha$ ), interferon gamma (IFN- $\gamma$ ) in umbilical blood were analysed using a kit for the enzyme-linked immunosorbent assay ProConIL-2, IFNgamma, TNF- $\alpha$ ("Protein Contour" Limited Liability Company, St. Petersburg).

The following software packages were used: Statistica version 6.0 and EXCEL 2003, SPSS 13.0, MegaStat. PolyAnalist 3.5 Pro package was used for the analysis of multidimensional nonlinear dependences.

Results Manifestations of the infectious process were not observed in all newborns within the first month of their life. From the end of the first month and up to the third month of life, clinical presentations of the infection, including viral infection, were observed in 15 newborns, cytomegalovirus DNA was detected in urine analyses that allowed diagnosing cytomegalovirus infection. In 22 newborns no clinical presentations of the infection were recorded. The control group was comprised of 15 newborns without infection.

Analysis of multidimensional nonlinear dependences using "PolyAnalist 3.5. Pro" package has shown factors which are significant for prognosis of the infectious process in the postnatal period: IL-2, TNF- $\alpha$, IFN- $\gamma$. Formula of dependence of the infectious process prognosis on the content of IL-2, TNF- $\alpha$, IFN- $\gamma$ in umbilical blood of newborns born by mothers with chronic inflammatory gynaecological diseases in case of a late detection of cytomegalovirus DNA was suggested: IL-2* TNF- $\alpha$ $<-527.79+4.1342 *$ IFN- $\gamma *$ TNF- $\alpha$.

If this inequality is fulfilled, we prognosticate an infectious process in the postnatal period. Accuracy is $85 \%$. If this inequality is not fulfilled, the infection will not develop. Accuracy is $91 \%$. $\mathrm{P}<0,000001$. Sensitivity is $87 \%$, specificity is $91 \%$. Positive predictive value is 9.6 ; negative predictive value is 7 .

Conclusions The formula is an early marker of the infectious process manifestation in newborns born by mothers with chronic inflammatory gynaecological diseases and it allows separating children of the risk group for the appropriate therapy prescription.

\section{G446(P) PROMOTING ENGAGEMENT OF CHILDREN AND YOUNG PEOPLE IN ALLERGY CLINIC VIA REAL TIME FEEDBACK TOOLS AND SOCIAL MEDIA}

A Brightwell, C Watkins, J Chapman. Department of Paediatrics, James Paget University Hospital, Great Yarmouth, UK

\subsection{6/archdischild-2015-308599.400}

Background Research shows that patients consider their overall experience of care to be of equal importance in quality, alongside clinical effectiveness and safety. ${ }^{1}$ The NHS constitution commits providers to encourage and welcome feedback on patients' healthcare experiences. ${ }^{2}$ The difficulty of hearing the voices of children and young people as users of NHS services is widely acknowledged, and finding better ways to collect feedback from children and developing the use of IT in feedback have been identified as key priorities. ${ }^{3}$

Aim We aimed to improve the collection of patient feedback in our district general hospital allergy clinic to promote engagement of children, young people and families.

Methods All children, young people and families attending a district general hospital 'one stop' multidisciplinary children's allergy clinic were invited to submit real time feedback using a 'business card' feedback tool. Participants were encouraged to submit brief one or two word feedback. Responses were then summarised using a 'word cloud' and were made freely available on social media and displayed weekly in allergy clinic. Patients and families are also invited to submit feedback via twitter.

Results The real time feedback tool has now been running for 18 months. Seasonal themed word clouds are generated to capture the attention of children and young people. Following a number of comments regarding the length of waiting time, preclinic information has now been developed to give more information on what to expect on the day of the appointment, including expected duration of visit.

Conclusion Collection of real time feedback using a business card tool and displaying via a word cloud on social media is a novel, feasible and popular method of collecting patient feedback in a paediatric allergy clinic which has led to service improvement and aligns with NHS priorities for engagement with children and young people.

\section{REFERENCES}

1 CornwellJ. What matters to patients? developing the evidence base for measuring and improving patient experience. National Nursing Research Unit, King's College London. Coventry: NHS Institute, 2011 Web publication

2 NHS Constitution, Department of Health 2013

3 Evans R. Celebrating the best of children and young people's experience of care. Patient Experience Network, NHS England, September 2013

\section{G447(P) THE INNATE IMMUNITY FACTORS IN CASE OF INTRAUTERINE HERPETIC INFECTION}

AYu Levkovich, AA Afonin, MA Levkovich, LV Kravchenko. Pediatric Department, Rostov Scientific-Research Institute of Obstetrics and Pediatrics, Rostov-On-Don, Russia

\subsection{6/archdischild-2015-308599.401}

Aim To reveal the role of innate immunity factors in the development of the generalised herpetic infection (HSV-1 and HSV-2) in newborn babies. 